\title{
Survival of Feral Cats, Felis catus (Carnivora: Felidae), on Mauna Kea, Hawai'i, Based on Tooth Cementum Lines ${ }^{1}$
}

\author{
Raymond M. Danner, ${ }^{2,3,6}$ Chris Farmer, ${ }^{2}$ Steven C. Hess, ${ }^{4}$ Robert M. Stephens, ${ }^{2,5}$ \\ and Paul C. Banko ${ }^{4}$
}

\begin{abstract}
Feral cats (Felis catus) have spread throughout anthropogenic and insular environments of the world. They now threaten many species of native wildlife with chronic depredation. Knowledge of feral cat population dynamics is necessary to understand their ecological effects and to develop effective control strategies. However, there are few studies worldwide regarding annual or lifetime survival rates in remote systems, and none on Pacific islands. We constructed the age distribution and estimated survival of feral cats in a remote area of Hawai'i Island using cementum lines present in lower canine teeth. Our data suggest annual cementum line formation. A log-linear model estimated annual survival $\geq 1 \mathrm{yr}$ of age to be 0.647 . Relatively high survival coupled with high reproductive output allows individual cats to affect native wildlife for many years and cat populations to rebound quickly after control efforts.
\end{abstract}

Feral cats (Felis catus) are considered by the World Conservation Union (IUCN) as one of the " 100 of the world's worst invasive alien species" (Lowe et al. 2000). They have been

\footnotetext{
${ }^{1}$ This research was funded by the Federal Highway Administration, the Natural Resources Partnership Program of the U.S. Geological Survey and the National Park Service, and the U.S. Geological Survey Wildlife and Terrestrial Resources Program and Invasive Species Programs. Portions of this research were performed under Cooperative Agreement 00003HS025 to the University of Hawai'i at Mānoa and Cooperative Agreement 3036 WS0012 to the University of Hawai'i at Hilo. Manuscript accepted 18 August 2009.

${ }^{2}$ Hawai'i Cooperative Studies Unit, Pacific Aquaculture and Coastal Resources Center, University of Hawai'i, Hilo, P.O. Box 44, Hawai'i National Park, Hawai'i 96718.

${ }^{3}$ Current address: Department of Biological Sciences, Virginia Polytechnic Institute and State University, 2125 Derring Hall, Blacksburg, Virginia 24061.

${ }^{4}$ Pacific Island Ecosystems Research Center, U.S. Geological Survey, Kìlauea Field Station, P.O. Box 44, Hawai'i National Park, Hawai'i 96718.

${ }^{5}$ Department of Land and Natural Resources, Division of Forestry and Wildlife, 19 East Kāwili Street, Hilo, Hawai'i 96720.

${ }^{6}$ Corresponding author (e-mail: rdanner@vt.edu).
}

Pacific Science (2010), vol. 64, no. 3:381-389

doi: 10.2984/64.3.381

(C) 2010 by University of Hawai'i Press

All rights reserved specifically implicated in at least 33 bird extinctions, primarily on islands, making them one of the most important causes of bird extinctions worldwide (Nogales et al. 2004). To develop more effective control strategies for feral cats, knowledge of their population dynamics based on survival, reproduction, and movements is required. There are some data on immigration and emigration (Edwards et al. 2001, Devillard et al. 2003, Hansen et al. 2007, Schmidt et al. 2007), as well as reproduction (van Aarde 1983, Pascal 1980), but survival is relatively unknown worldwide. Most studies of feral cat survival rates are from anthropogenic landscapes (Devillard et al. 2003, Schmidt et al. 2007) where the mortality factors tend to be human-related (e.g., cars) or as part of eradication programs (Short et al. 1997, Bester et al. 2002, Rodríguez et al. 2006). There are few studies of natural mortality in remote systems (van Aarde 1983, 1984, Pascal 1980) and none on Pacific islands.

Feral cats became abundant in forests of the Hawaiian Islands soon after their introduction in the late 1700s (Rothschild 1893, Perkins 1903). They were subsequently reported to be notorious and harmful predators that contributed to the decline and extinction of some Hawaiian bird species (Perkins 1903, Ralph and van Riper 1985, Stone 1985, 
Smucker et al. 2000). Feral cats in Hawai'i prey upon endangered forest birds (Laut et al. 2003, Hess et al. 2004) and terrestrial birds that nest near the ground (Kowalsky et al. 2002), as well as colonial nesting seabirds (Hu et al. 2001, Smith et al. 2002, Hess et al. 2007). In addition, cats are the definitive host of Toxoplasma gondii, a parasite that has killed individuals of several native and introduced wildlife species (Work et al. 2000, 2002, Honnold et al. 2005). Feral cats range throughout the Hawaiian Islands from high-density colonies near coastal areas where pets are frequently abandoned and fed by people (Winter 2003), to remote, lowdensity populations in montane forests and subalpine areas of Maui (Simons 1983) and Hawai'i Island (Tomich 1986, Hu et al. 2001, Hansen et al. 2007). Feral cats, particularly males, occupy large home ranges and disperse long distances in Hawai'i (Hansen et al. 2007, Goltz et al. 2008).

Tooth cementum lines are ideal for studies of wild mammal population dynamics because they may provide more precise age estimates, especially for older individuals, than methods that rely on pelage, dentition, or eye lens weight (Dimmick and Pelton 1996). This method is effective for many mammal species (Crowe 1972, Spinage 1976, Grue and Jensen 1979), including F. catus (Pascal and Castanet 1978, Grue and Jensen 1979, van Aarde 1983, Daniels et al. 1998), but as yet has not been widely used. Our objectives were to construct the age distribution and estimate the survival rate of feral cats on Mauna Kea, Hawai'i Island, based on the number of tooth cementum lines.

\section{Study Area}

We collected samples from two sites on Mauna Kea, Hawai'i Island, one on the west slope (WMK, $19^{\circ} 49^{\prime} \mathrm{N}, 155^{\circ} 36^{\prime} \mathrm{W}$ ) and one on the north (NMK, $19^{\circ} 54^{\prime} \mathrm{N}, 155^{\circ}$ $27^{\prime} \mathrm{W}$ ). Both sites are in federally designated critical habitat for palila (Loxioides bailleui), an endangered Hawaiian honeycreeper (U.S. Fish and Wildlife Service 1977). The sites are approximately $18 \mathrm{~km}$ apart, and although separated by large expanses of bare rock, Goltz et al. (2008) detected cat movements between them. Annual temperature values range between $9.6^{\circ}$ and $12.2^{\circ} \mathrm{C}$. The $58-\mathrm{yr}$ mean annual rainfall was $511 \mathrm{~mm}$, and a pronounced wet season occurs from July to September (Juvik et al. 1993).

Both sites are dry subalpine woodlands, and species abundance and plant phenology vary along an elevation gradient (Banko et al. 2002). The dominant vegetation includes māmane (Sophora chrysophylla) and naio (Myoporum sandwicense) trees, with pükiawe (Leptecophylla tameiameiae) and 'āheabea (Chenopodium oabuense) shrubs. The understory is primarily exotic grasses such as Dactylis glomerata, Holcus lanatus, Anthoxanthum odoratum, and Poa pratensis. Feral cats and small Indian mongooses (Herpestes auropunctatus) are common at both sites. The house mouse (Mus musculus), an introduced mammal, and numerous native and introduced species of birds are abundant prey for feral cats (van Riper 1978, Snetsinger et al. 1994, Hess et al. 2004, Hess et al. 2007). The abundance of these prey changed dramatically throughout the study period (U.S. Geological Survey, unpubl. data).

\section{MATERIALS AND METHODS}

\section{Data Collection}

We placed 106 live traps (Tomahawk) (66 by 23 by $23 \mathrm{~cm}$ ) on transects perpendicular to elevation contours on WMK and NMK from 1,700 to $2,900 \mathrm{~m}$ elevation to capture and euthanize feral cats in compliance with University of Hawai'i IACUC Protocol 97-063. WMK was sampled during 2 July-13 August 2003 ( $n=15$ cats) and NMK during 18 November 2003-15 March 2005 ( $n=13$ cats). We determined sex by examination of gonads during necropsy. We placed jaws into an $80^{\circ} \mathrm{C}$ water bath for $2-4 \mathrm{hr}$ to loosen teeth, extracted one $(n=6)$ or two $(n=22)$ lower canine teeth from each jaw, and sent all teeth $(n=50)$ to Matson's Laboratory (Milltown, Montana; www.MatsonsLab.com). The standard model for estimating age from ce- 
mentum in felids is based on lower canines (Matson 1981). Matson's processed the WMK samples in January 2004 and the NMK samples in February 2006. Laboratory analysts knew the dates of tooth collection but not sex, location, or individual identification of duplicate teeth. Most samples $(n=49)$ were longitudinally sectioned, dyed, and evaluated for cementum line patterns.

Alternating wide light-colored cementum bands and thin dark-colored cementum lines are deposited yearly in many mammals (Grue and Jensen 1979). The cause of their formation is imprecisely known but may include both endogenous and exogenous controls. Endogenous control, such as hormone cycles, was supported for humans (WittwerBackofen et al. 2004) and feral cats (van Aarde 1983), which deposited annual cementum lines despite relatively constant environmental conditions and diets. Alternatively, dietary shifts caused by low food availability may slow cementum growth and alter the mechanical action of chewing, leading to cementum line formation that may or may not occur annually (Lieberman 1993). For example, cementum lines in rhesus monkeys (Macaca mulatta) were correlated with dry periods and presumably caused by episodes of lower food abundance or quality (Kay and Cant 1988). Given the unimodal patterns of māmane tree phenology (Banko et al. 2002) and rainfall on Mauna Kea (Juvik et al. 1993), we predicted that feral cats would form annual cementum lines regardless of endogenous or exogenous control.

Age was determined for each tooth according to a model for bobcat (Lynx rufus) and classified into one of three certainty categories, based on how closely the sample matched that model, including the clarity of cementum lines, morphology, and estimated age (Matson 1981). Samples that very nearly matched the standard model were given a certainty score of "A" and an estimated age. Samples for which there was histological evidence to support the result were given a score of "B" and a range of ages. Samples that poorly matched the standard model were given a score of "C" and a potential age range. Age was determined for one tooth from a sample pair to class zero by inspection of morphology without sectioning (Matson 1981).

\section{Data Analysis}

We compared the left versus right lower canines (when both were present) to assess repeatability. We constructed age distributions and log-linear models with the Newton iterative method to estimate the annual survival of feral cats (PROC NLIN [SAS Institute 1999]). The model equation took the form $Y=\exp \left(B_{0}+\left(B_{1} * X\right)\right)$, where $X$ was the age category and $Y$ was the predicted number of cats in category $X$. It was necessary to estimate a model intercept $\left(B_{0}\right)$, but this was not biologically meaningful by itself. We interpreted the exponent of $B_{1}$ as the estimate of annual survival, which approximated a monotonic decline in an age frequency, and $95 \%$ confidence intervals (CIs) of survival were interpreted as the exponents of $95 \%$ CIs of $B_{1}$.

\section{RESULTS}

The pattern of annulus formation appeared to be regular, with a recurring light-dark cementum sequence. In addition, one female had been captured and released 4 yr earlier and had five cementum lines on the higherquality tooth sample, suggesting that one or fewer lines were deposited per year. Of the 49 sectioned teeth, cementum characteristics in $36(73 \%)$ of the sections were given certainty scores of A, 13 (27\%) were given scores of $\mathrm{B}$, and none was given a score of $\mathrm{C}$ (Appendix). There was a discrepancy in determining the age of $8 / 22(36 \%)$ cats' left versus right teeth (all from the first batch, WMK), with a mean variation of $1.5 \mathrm{yr}$ and a maximum of $4 \mathrm{yr}$. For sample pairs that were given age ranges, two pairs had different, yet overlapping, ranges, and one pair had the same range. When there was an age discrepancy, we used the age from the tooth with the higher certainty score $(n=5)$ for our survival analyses. If both teeth had the same certainty score but different ages 


\section{TABLE 1}

Frequency Distributions of Ages of Feral Cats Determined by Tooth Cementum Annuli from West Mauna Kea and North Mauna Kea, Hawai'i, 2003-2005

\begin{tabular}{cccccc}
\hline \hline & \multicolumn{2}{c}{ West Mauna Kea } & & \multicolumn{2}{l}{ North Mauna Kea } \\
\cline { 2 - 3 } \cline { 5 - 6 } Age & Male & Female & & Male & Female \\
\hline 0 & 4 & 0 & & 4 & 0 \\
1 & 3 & 0 & & 0 & 3 \\
2 & 3 & 1 & & 2 & 2 \\
3 & 1 & 0 & & 0 & 2 \\
5 & 0 & 2 & & 0 & 0 \\
11 & 1 & 0 & & 0 & 0 \\
Total & 12 & 3 & & 6 & 7 \\
\hline
\end{tabular}

Note: Ages not represented in the sample are not shown.

$(n=3)$, we used the maximum age, assuming that some cementum lines may not have been visible in one of the teeth.

We sampled a similar number of cats from WMK $(n=15)$ and NMK $(n=13)$, but there were more males $(n=18)$ than females $(n=10)$, especially on WMK (Table 1$)$. All of the eight cats in age class zero were male, and the only individual $\geq 10 \mathrm{yr}$ old was also male. Because of the overall male bias, we calculated survival estimates for the entire sample, for animals $\geq 1 \mathrm{yr}$ with both sexes combined and separately, and for animals aged 1-5 yr with both sexes.

The log-linear model including all individuals produced an annual survival rate of 0.704 (Figure 1, Table 2). Survival estimates and corresponding CIs were similar between the two sites. Because female and overall survival estimates could be inflated by the lack of females of age zero, we estimated survival for cats $\geq 1$ yr old. In that data set, CIs overlapped between the sexes, and the estimate for both sexes combined was slightly lower (0.647) than the model that included all individuals of all ages (Table 2). Calculating the annual survival for both sexes, but including only cats aged 1-5 yr, did not significantly change the survival estimate (0.678), although the $95 \%$ CI was wide $(0.348-1.321)$.

\section{DISCUSSION}

Analysis of tooth cementum lines allowed us to construct the age distribution and estimate

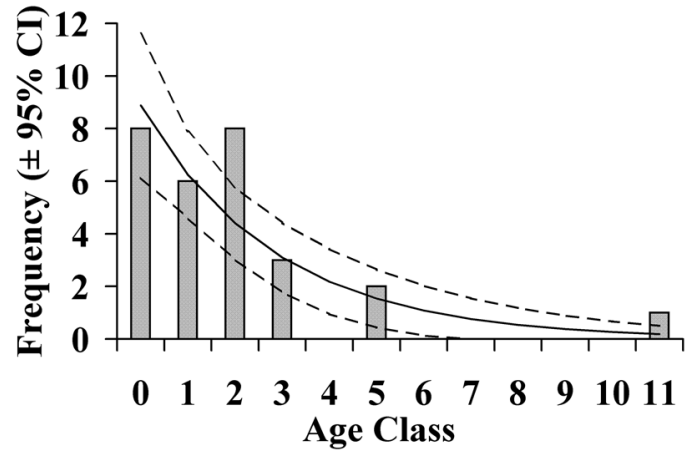

Figure 1. Age distributions of feral cats (sample = gray bars, predicted $\pm 95 \% \mathrm{CI}=$ solid line with dashed line envelope) from tooth cementum annuli on Mauna Kea, Hawai'i, 2003-2005 (all individuals). Predicted values were calculated from a $\log$-linear model $\left[Y=\exp \left(B_{0}+\right.\right.$ $\left.\left(B_{1} * X\right)\right)$ ] where exponent $B_{1}$ is the survival estimate. Lower CI set to zero when predicted negative (ages 711).

\section{TABLE 2}

Annual Survival Estimates and 95\% Confidence Intervals for Feral Cats Whose Age Was Determined by Tooth Cementum Annuli from West Mauna Kea and North Mauna Kea, Hawai'i, 2003-2005

\begin{tabular}{lcc}
\hline \hline Data Set & $\begin{array}{c}\text { Survival } \\
\text { Estimate }\end{array}$ & $\begin{array}{c}95 \% \\
\text { Confidence } \\
\text { Interval }\end{array}$ \\
\hline Both sexes, all ages & 0.704 & $0.596-0.832$ \\
Both sexes, West Mauna Kea & 0.720 & $0.591-0.877$ \\
Both sexes, North Mauna Kea & 0.691 & $0.580-0.823$ \\
Both sexes, $\geq 1$ yr & 0.647 & $0.499-0.840$ \\
Males, $\geq 1$ yr & 0.614 & $0.417-0.903$ \\
Females, $\geq 1$ yr & 0.759 & $0.420-1.370$ \\
Both sexes, $1-5$ yr & 0.678 & $0.348-1.321$ \\
\hline
\end{tabular}

Note: Each data set was fit with a separate log-linear model to estimate survival.

annual survival of feral cats on Mauna Kea. Our study was based on the assumption that tooth cementum data reflect a pattern of annual formation and therefore age. This assumption is supported by (1) the presence of cementum lines in the teeth, (2) one recaptured cat that deposited at most one line per year, and (3) the seasonality in subalpine Mauna Kea, which is observed in māmane tree phenology (Banko et al. 2002), temperature, and rainfall (Juvik et al. 1993) that may 
induce annulus formation. Proving seasonal annulus formation would require samples from a large number of cats collected throughout the year. However, some tooth sections from July-August 2003 had a thick layer of cellular cementum (usually formed during seasons of rapid somatic growth) as the outer, most recently formed layer, which is typical of teeth collected in early summer from strongly seasonal climates (G. Matson, pers. comm.). Inconsistencies in age determined within individual cats from WMK could be due to errors in extraction or preparation, because all eight conflicting teeth were from the same batch.

Our results suggest two possible biases in our study. First, the male bias in age class zero may reflect a higher capture probability, which would generate an inaccurate age distribution. Van Aarde (1983) found that feral cat sex ratios are near $1: 1$ at birth, suggesting that our age zero results were skewed by capture probabilities. Juvenile males are typically the dispersers in mammals (Greenwood 1980), and Hansen et al. (2007) found that there was male-biased dispersal of unknownaged cats on Mauna Kea, which could lead to higher juvenile male capture probabilities. Excluding age zero individuals from our model lowered the annual survival estimate, but it was still within the $95 \%$ CI for the complete data set. Second, the assumption of constant annual survival across all age classes may also bias results. Much larger samples would be necessary to determine age-specific mortality rates. Long-lived mammals typically have high mortality in their first year that may need to be modeled separately (Eberhardt 1985). Van Aarde (1983) found feral cat survival in the first year to be 0.204 , but survival rates at ages from 2-6 yr all exceeded 0.809. Studies of cat colonies near human settlements also found low kitten survival: $0.128-0.48$ for 6- to 8-week-old kittens (Jemmett and Evans 1977, Scott et al. 1978), 0.25 at 6 months of age (Nutter et al. 2004), and 0.095 at 10 months (though most of the mortality occurred in the first 6 months) (Izawa and Ono 1986). In addition, van Aarde (1983) found a sharp decrease in survival from age 5 (0.944) to 7 (0.642). Because 27/
28 of our individuals were $\leq 5 \mathrm{yr}$, we calculated survival from yr $1-5$. This changed the estimate little, but increased the $95 \%$ CI greatly. Given the sex bias in sampling for age zero, we feel that our most accurate annual survival estimate for cats on Mauna Kea is based on only individuals $\geq 1 \mathrm{yr}$.

Our survival estimate for individuals $\geq 1 \mathrm{yr}$ (0.647) was lower than for the overall population of feral cats in tundra habitat on Marion Island (0.810), where mortality factors were also natural (van Aarde 1983). Reported longevity was high on Marion Island (8-9 yr [van Aarde 1984]) and the Kerguelen Islands (8 yr [Pascal 1980]). Our survival estimate from the Mauna Kea wilderness was more similar to those from feral cats living in anthropogenic environments (0.57-0.88 [Kaeuffer et al. 2004, Schmidt et al. 2007]) versus those from the remote oceanic islands given earlier. Kaeuffer et al. (2004) calculated longevity of male cats in France to be $2.85 \mathrm{yr}$ in an urban setting and $2.63 \mathrm{yr}$ for a rural town, and females were $3.70 \mathrm{yr}$ and $4.35 \mathrm{yr}$, respectively. However, Warner (1985) reported low longevity in farm cats in Illinois, U.S.A., where less than $3 \%$ lived $\geq 4 \mathrm{yr}$, and only $1 \%$ lived $\geq 7 \mathrm{yr}$, apparently from mortality by humans and dogs. The survival rate of feral cats on Mauna Kea suggests relatively high longevity, which is exemplified by two 5 -yr-old animals and one $11 \mathrm{yr}$ old. High longevity on Mauna Kea exists despite the presence of feline leukemia virus (16.2\% prevalence) and feline immunodeficiency virus (8.8\% prevalence) (Danner et al. 2007).

There are three major ecological and conservation implications of the relatively high survival and longevity of cats on Mauna Kea, Hawai'i. First, depredation of wildlife continues throughout the life of cats and into old age, confirmed by an 11-yr-old male with a bird in its digestive tract, despite the fact that this individual was missing over half of its teeth (U.S. Geological Survey, unpubl. data). Therefore, the cumulative effect of predation by a single cat throughout its life is likely to be substantial. Second, approximately 37\% of cats trapped on Mauna Kea were infected with $T$. gondii. Thus, high longevity may increase the chance of an individual transmit- 
ting toxoplasmosis to native Hawaiian species (Danner et al. 2007). Last, each individual female is capable of producing many offspring. We found that $14.6 \%(7 / 48)$ of female cats trapped on WMK were pregnant, with an average of 3.6 embryos $(n=5$, range $=2-5$, $\mathrm{SD}=1.14$ [U.S. Geological Survey, unpubl. data]). Pascal (1980) and van Aarde (1983) found female feral cats to be reproductive at all ages captured (1-8 yr of age), often producing two litters per season. Prolific reproduction coupled with high survival would allow even a few cats to cause a rapid population rebound after control efforts. This is consistent with observations after extended removal sessions on Mauna Kea. Hess et al. (2004) reported that despite a reduction in capture rates during an initial trapping session, capture rates were substantially higher after a 15-month hiatus. Therefore, short of total eradication, which is unlikely, almost continuous control may be necessary to effectively reduce cat populations and minimize their impacts on native species.

\section{ACKNOWLEDGMENTS}

We thank the Hawai'i Division of Forestry and Wildlife for permission to work on Mauna Kea. We thank D. Nelson and R. Aldredge for preparing samples. We also thank two anonymous reviewers for many helpful comments. Any use of trade, product, or firm names in this publication is for descriptive purposes only and does not imply endorsement by the U.S. Government.

\section{Literature Cited}

Banko, P. C., P. T. Oboyski, J. W. Slotterback, S. J. Dougill, D. M. Goltz, L. Johnson, M. E. Laut, and T. C. Murray. 2002. Availability of food resources, distribution of invasive species, and conservation of a Hawaiian bird along a gradient of elevation. J. Biogeogr. 29:789-808.

Bester, M. N., J. P. Bloomer, R. J. van Aarde, B. H. Erasmus, P. J. J. van Rensburg, J. D. Skinner, P. G. Howell, and T. W. Naude. 2002. A review of the successful eradica- tion of feral cats from sub-Antarctic Marion Island, southern Indian Ocean. S. Afr. J. Wildl. Res. 32:65-73.

Crowe, D. M. 1972. The presence of annuli in bobcat tooth cementum layers. J. Wildl. Manage. 36:1330-1332.

Daniels, M. J., D. Balharry, D. Hirst, A. C. Kitchener, and R. J. Aspinall. 1998. Morphological and pelage characteristics of wild living cats in Scotland: Implications for defining the 'wildcat.' J. Zool. 244:231-247.

Danner, R. M., D. M. Goltz, S. C. Hess, and P. C. Banko. 2007. Evidence of feline immunodeficiency virus, feline leukemia virus, and Toxoplasma gondii in feral cats on Mauna Kea, Hawaii. J. Wildl. Dis. 43:315-318.

Devillard, S., L. Say, and D. Pontier. 2003. Dispersal pattern of domestic cats (Felis catus) in a promiscuous urban population: Do females disperse or die? J. Anim. Ecol. 72:203-211.

Dimmick, R. W., and M. R. Pelton. 1996. Criteria of age and sex. Pages 169-214 in T. A. Bookhout, ed. Research and management techniques for wildlife and habitats. The Wildlife Society, Bethesda, Maryland.

Eberhardt, L. L. 1985. Assessing the dynamics of wild populations. J. Wildl. Manage. 49:997-1012.

Edwards, G. P., N. De Preu, B. J. Shakeshaft, I. V. Crealy, and R. M. Paltridge. 2001. Home range and movements of male feral cats (Felis catus) in a semiarid woodland environment in central Australia. Austral Ecol. 26:93-101.

Goltz, D. M., S. C. Hess, K. W. Brinck, P. C. Banko, and R. M. Danner. 2008. Home range and movements of feral cats on Mauna Kea, Hawai'i. Pac. Conserv. Biol. 14:177-184.

Greenwood, P. J. 1980. Mating systems, philopatry and dispersal in birds and mammals. Anim. Behav. 28:1140-1162.

Grue, H., and B. Jensen. 1979. Review of formation of incremental lines in tooth cementum of terrestrial mammals. Dan. Rev. Game Biol. 11:1-48. 
Hansen, H., S. C. Hess, D. Cole, and P. C. Banko. 2007. Using population genetic tools to develop a control strategy for feral cats (Felis catus) in Hawai'i. Wildl. Res. 34:587-596.

Hess, S. C., P. C. Banko, D. M. Goltz, R. M. Danner, and K. W. Brinck. 2004. Strategies for reducing feral cat threats to endangered Hawaiian birds. Proc. Vertebr. Pest Conf. 21:21-26.

Hess, S. C., H. Hansen, D. Nelson, R. Swift, and P. C. Banko. 2007. Diet of feral cats in Hawai'i Volcanoes National Park. Pac. Conserv. Biol. 13:244-249.

Honnold, S. P., R. Braun, D. P. Scott, C. Sreekumar, and J. P. Dubey. 2005. Toxoplasmosis in a Hawaiian monk seal (Monachus schauinslandi). J. Parasitol. 91:695697.

Hu, D., C. Glidden, J. S. Lippert, L. Schnell, J. S. MacIvor, and J. Meisler. 2001. Habitat use and limiting factors in a population of Hawaiian dark-rumped petrels on Mauna Loa, Hawai'i. Stud. Avian Biol. 22:234-242.

Izawa, M., and Y. Ono. 1986. Motheroffspring relationship in the feral cat population. J. Mammal. Soc. Jpn. 11:2734.

Jemmett, J. E., and J. M. Evans. 1977. A survey of sexual behavior and reproduction in female cats. J. Small Anim. Pract. 18:3137.

Juvik, J. O., D. Nullet, P. Banko, and K. Hughes. 1993. Forest climatology near the tree line in Hawaii. Agric. For. Meteorol. 66:159-172.

Kaeuffer, R., D. Pontier, S. Devillard, and N. Perrin. 2004. Effective size of two feral domestic cat populations (Felis catus L.): Effect of the mating system. Mol. Ecol. 13:483-490.

Kay, R. F., and J. G. H. Cant. 1988. Age assessment using cementum annulus counts and tooth wear in a free-ranging population of Macaca mulatta. Am. J. Primatol. 15:1-15.

Kowalsky, J. R., T. K. Pratt, and J. C. Simon. 2002. Prey taken by feral cats (Felis catus) and barn owls (Tyto alba) in Hanawi Natu- ral Area Reserve, Maui, Hawai'i. 'Elepaio 62:127-130.

Laut, M. E., P. C. Banko, and E. M. Gray. 2003. Nesting behavior of Palila, as assessed from video recordings. Pac. Sci. 57:385-392.

Lieberman, D. E. 1993. Life history variables preserved in dental cementum microstructure. Science (Washington, D.C.) 261:1162-1164.

Lowe, S., M. Browne, S. Boudjelas, and M. De Poorter. 2000. 100 of the world's worst invasive alien species: A selection from the global invasive species database. The Invasive Species Specialists Group of the Species Survival Group of the World Conservation Union. First published in Aliens 12, December 2000. Reprinted November 2004. Hollands Printing, Auckland, New Zealand.

Matson, G. M. 1981. Workbook for cementum analysis. Matson's Laboratory, Milltown, Montana.

Nogales, M., A. Martín, B. R. Tershy, C. J. Donlan, D. Veitch, N. Puerta, B. Wood, and J. Alonso. 2004. A review of feral cat eradication on islands. Conserv. Biol. 18:310-319.

Nutter, F. B., J. F. Levine, and M. K. Stoskopf. 2004. Reproductive capacity of freeroaming domestic cats and kitten survival rate. J. Am. Vet. Med. Assoc. 225:13991402.

Pascal, M. 1980. Structure et dynamique de la population de chats harets de l'archipiel des Kerguelen. Mammalia 44:161182.

Pascal, M., and J. Castanet. 1978. Age determination of feral cats in the Kerguelen Islands, Indian Ocean. Terre Vie 32:529556.

Perkins, R. C. L. 1903. Vertebrata. Pages 365-466 in D. Sharp, ed. Fauna Hawaiiensis. Vol. 1, part IV. The University Press, Cambridge, United Kingdom.

Ralph, C. J., and C. van Riper III. 1985. Historical and current factors affecting $\mathrm{Ha}-$ waiian native birds. Pages 7-42 in S. A. Temple, ed. Bird conservation. 2nd ed. International Council for Bird Preservation, 
United States Section. The University of Wisconsin Press, Madison.

Rodríguez, C., R. Torres, and H. Drummond. 2006. Eradicating introduced mammals from a forested tropical island. Biol. Conserv. 130:98-105.

Rothschild, W. 1893. The avifauna of Laysan and the neighboring islands: With a complete history to date of birds of the Hawaiian possessions. R. H. Porter, London.

SAS Institute. 1999. SAS/STAT user's guide. Version 8. SAS Institute, Cary, North Carolina.

Schmidt, P. M., R. R. Lopez, and B. A. Collier. 2007. Survival, fecundity, and movements of free-roaming cats. J. Wildl. Manage. 71:915-919.

Scott, F. W., C. Geissinger, and R. Peltz. 1978. Kitten mortality survey. Feline Pract. 8:31-34.

Short, J., B. Turner, D. A. Risbey, and R. Carnamah. 1997. Control of feral cats for nature conservation. II. Population reduction by poisoning. Wildl. Res. 24:703714.

Simons, T. R. 1983. Biology and conservation of the endangered Hawaiian darkrumped petrel (Pterodroma phaeopygia sandwichensis). National Park Service, Cooperative Studies Unit, University of Washington, CPSU/UW 83-2, Seattle.

Smith, D. G., J. T. Polhemus, and E. A. VanderWerf. 2002. Comparison of managed and unmanaged wedge-tailed shearwater colonies on $\mathrm{O}^{6}$ ahu: Effects of predation. Pac. Sci. 56:451-457.

Smucker, T. D., G. D. Lindsey, and S. M. Mosher. 2000. Home range and diet of feral cats in Hawaii forests. Pac. Conserv. Biol. 6:229-237.

Snetsinger, T. J., S. G. Fancy, J. C. Simon, and J. D. Jacobi. 1994. Diets of owls and feral cats in Hawaii. 'Elepaio 54:47-50.

Spinage, C. A. 1976. Incremental cementum lines in the teeth of tropical African mammals. J. Zool. (Lond.) 178:117-131.
Stone, C. P. 1985. Alien animals in Hawai'i's native ecosystems: Toward controlling the adverse effects of introduced vertebrates. Pages 251-297 in C. P. Stone and J. M. Scott, Hawai'i's terrestrial ecosystems: Preservation and management. Cooperative National Park Resources Studies Unit, University of Hawai'i, Honolulu.

Tomich, P. Q. 1986. Mammals in Hawai'i. Bishop Museum Press, Honolulu.

U.S. Fish and Wildlife Service. 1977. Determination of critical habitat for six endangered species. Fed. Register 42:40,68540,690.

van Aarde, R. J. 1983. Demographic parameters of the feral cat Felis catus population at Marion Island. S. Afr. J. Wildl. Res. 13:12-16.

. 1984. Population biology and the control of feral cats on Marion Island. Acta Zool. Fenn. 172:281-288.

van Riper III, C. 1978. The breeding ecology of the Amakihi (Loxops virens) and Palila (Psittirostra bailleui) on Mauna Kea, Hawaii. Ph.D. diss., University of Hawai'i at Mānoa, Honolulu.

Warner, R. E. 1985. Demography and movements of free-ranging domestic cats in rural Illinois. J. Wildl. Manage. 49:340-346.

Winter, L. 2003. Popoki and Hawai'i's native birds. 'Elepaio 63:43-46.

Wittwer-Backofen, U., J. Gampe, and J. W. Vaupel. 2004. Tooth cementum annulation for age estimation: Results from a large age-known study. Am. J. Phys. Anthropol. 123:119-129.

Work, T. M., J. G. Massey, D. S. Lindsay, and J. P. Dubey. 2002. Toxoplasmosis in three species of native and introduced $\mathrm{Ha}$ waiian birds. J. Parasitol. 88:1040-1042.

Work, T. M., J. G. Massey, B. A. Rideout, C. H. Gardiner, D. B. Ledig, O. C. H. Kwok, and J. P. Dubey. 2000. Fatal toxoplasmosis in free-ranging endangered 'Alalā from Hawai'i. J. Wildl. Dis. 36:205-212. 


\section{Appendix}

Tooth Cementum Annuli Data for Feral Cats from West Mauna Kea and North Mauna Kea, Hawai'i, 2003-2005

\begin{tabular}{|c|c|c|c|c|c|c|c|c|c|}
\hline \multicolumn{5}{|c|}{ West Mauna Kea } & \multicolumn{5}{|c|}{ North Mauna Kea } \\
\hline Sample ${ }^{a}$ & Sex & Certainty Score & Age & Age Range & Sample ${ }^{a}$ & Sex & Certainty Score & Age & Age Range \\
\hline 1a & M & $\mathrm{A}$ & 0 & - & $1 \mathrm{a}$ & $M$ & $\mathrm{~A}$ & 0 & - \\
\hline $1 \mathrm{~b}$ & M & A & 1 & - & $1 b$ & $M$ & $\mathrm{~A}$ & 0 & - \\
\hline $2 \mathrm{a}$ & M & $\mathrm{A}$ & 1 & - & $2 \mathrm{a}$ & $M$ & A & 0 & - \\
\hline $2 \mathrm{~b}$ & M & A & 0 & - & $2 \mathrm{~b}^{b}$ & $M$ & A & 0 & - \\
\hline $3 \mathrm{a}$ & M & A & 3 & - & $3 a$ & $M$ & A & 0 & - \\
\hline $3 b$ & M & A & 2 & - & $3 b$ & $M$ & A & 0 & - \\
\hline $4 a$ & M & A & 0 & - & $4 a$ & $M$ & A & 0 & - \\
\hline $4 b$ & M & B & 1 & $1-2$ & $4 b$ & M & A & 0 & - \\
\hline $5 \mathrm{a}$ & M & $\mathrm{A}$ & 0 & - & $5 \mathrm{a}$ & $\mathrm{F}$ & A & 1 & - \\
\hline $5 b$ & M & B & 1 & $1-2$ & $5 b$ & $\mathrm{~F}$ & A & 1 & - \\
\hline $6 a$ & $M$ & A & 1 & - & $6 a$ & $\mathrm{~F}$ & A & 1 & - \\
\hline $6 \mathrm{~b}$ & M & B & 1 & $1-2$ & $6 \mathrm{~b}$ & $\mathrm{~F}$ & A & 1 & - \\
\hline $7 \mathrm{a}$ & M & A & 0 & - & $7 \mathrm{a}$ & $\mathrm{F}$ & A & 1 & - \\
\hline $7 b$ & M & B & 2 & $1-2$ & $7 b$ & $\mathrm{~F}$ & A & 1 & - \\
\hline $8 a$ & M & A & 2 & - & $8 a$ & $M$ & A & 2 & - \\
\hline $8 \mathrm{~b}$ & M & B & 3 & $2-3$ & $8 b$ & $M$ & A & 2 & - \\
\hline $9 \mathrm{a}^{c}$ & $\mathrm{~F}$ & A & 5 & - & $9 \mathrm{a}$ & $\mathrm{F}$ & A & 3 & - \\
\hline $9 b^{c}$ & $\mathrm{~F}$ & B & 1 & $1-2$ & $9 \mathrm{~b}$ & $\mathrm{~F}$ & A & 3 & - \\
\hline $10 \mathrm{a}$ & F & B & 2 & $2-3$ & $10 \mathrm{a}$ & $\mathrm{F}$ & A & 3 & - \\
\hline $10 \mathrm{~b}$ & $\mathrm{~F}$ & B & 2 & $1-2$ & $10 \mathrm{~b}$ & $\mathrm{~F}$ & A & 3 & - \\
\hline 11 & $M$ & A & 0 & - & $11 \mathrm{a}$ & $M$ & B & 2 & $2-3$ \\
\hline 12 & M & A & 2 & - & $11 \mathrm{~b}$ & $M$ & B & 2 & $1-3$ \\
\hline 13 & $\mathrm{~F}$ & A & 5 & - & $12 \mathrm{a}$ & $\mathrm{F}$ & B & 2 & $2-3$ \\
\hline 14 & M & A & 11 & $10-12$ & $12 \mathrm{~b}$ & $\mathrm{~F}$ & B & 2 & $2-3$ \\
\hline 15 & M & B & 2 & $1-2$ & 13 & $\mathrm{~F}$ & A & 2 & - \\
\hline
\end{tabular}

Note: Samples from each site were processed in separate batches.

a Pairs of teeth from the same individual are denoted by letters.

${ }^{b}$ Age determined by morphological inspection.

${ }^{c}$ Individual had been captured and released 4 yr earlier. 
